\title{
Formation of the Individual's Technological Culture in General Education and Professional School
}

\author{
Sergey Alekseevich Sedov \\ Kazan Federal University, Russian Federation, 423600, Yelabuga, Kazanskaya Street, 89
}

\section{Doi:10.5901/mjss.2015.v6n4s1p71}

\begin{abstract}
In this survey we made an attempt to justify the technological culture of the person as a result of the development of basic educational programs in modern education and vocational school. Technological culture of the person is represented in the form of a two-tier structure: horizontal and vertical, where the horizontal one - is a substructure consisting of the technological vision, technological prowess and technological behavior, and the vertical structure shows the relationship of technological outlook, technological thinking and creative abilities of students. The article gives a review of the problems of the individual's technological culture's formation in the educational institutions and also promising areas for further researches are highlighted.
\end{abstract}

Keywords: technological education, technological training, technological culture of the individual.

\section{Introduction}

Rapid transition of Russian society to new forms of economic activity has led to an increase in the need of active, adventurous, competent and responsible professionals. In the training of such specialists not only professional education plays an important role, but also a secondary school as a social institution, lays the groundwork for future career choices and further professional education. Market demand for the skilled employees, engineers has determined the social significance of technological education.

Significant changes in the content of technological education are implemented through Federal (new) state educational standards. One of these changes should be called the public perception of the results of basic educational programs' development. Modern technological training at school, at a secondary vocational school and through higher education is focused on the occupational mobility of a young man and a wide variety of professional activities. Variety of competencies, which are required for skilled workers and engineers, has actualized the issue of highlighting the single method to measure the person's readiness to the world of labour. The individual's technological culture is proposed to be such a measure. Essence, structure and problems of its formation in educational institutions formed the basis of our study.

\section{Methods}

Object of study: technological education.

Subject of research: the formation of a technological culture in general and vocational schools.

Objective is to investigate the problems of formation of the individual's technological culture in general and vocational schools.

Research objectives:

1) to discover the essence of the individual's technological culture in the context of technological education;

2) to identify the structure of the technological culture of the person;

3) to investigate the reasons causing the low efficiency of technological education in the modern school.

Methods:

- theoretical: analysis of the literature, the study and synthesis of teaching experience, methods of abstraction and specification;

- empirical: the study of teaching and program documentation of a comprehensive school, observation, inquiry.

The reliability and validity of the results of the study are provided by a variety of informational sources, comprehensive study of the scientific literature on the survey; validity of the research methodology, using a set of scientific methods, adequate to the object, subject, purpose and objectives of the survey. 


\section{Results}

\subsection{The essence of the individual's technological culture in the context of the technological education}

Analysis of modern Russian society, especially in transition period, raises the question of new approaches to the study of the laws of its development. Existing stereotypes in education at some moment became irrelevant. There was a change of stereotypes, perceptions that have been erected in the category of rules of a certain standard, and their existence in the public mind was predetermined. Changing of educational stereotypes has become a prerequisite of a human adaptation to the new economic situation. Thus, at present there is a fracture of priority in choosing a speciality, which has a positive effect on the improvement of the economic situation, predetermining competitiveness and investment attractiveness of Russia, as well as the quality of the training of future engineers (Sedov and Valiev, 2013).

The study of foreign experience gives reason to note a certain similarity of the society's modern requirements to the education, the quality of which now depends on the level of satisfaction with the production of qualified personnel. So, the question of production staffing in the US begins to be solved in high school courses with the vocational training and also in vocational oriented education of the students (Grubb, 1995, 1996; Dutton, 1996). Canadian schools build their work on the curriculum, combining alive and professional orientation to the study of technological disciplines (Wejk, 1996).

The demand on the labor market of skilled workers, engineers determines the social importance of technological education. In the definition of "technological education" we adhere to the A. V. Titov's position, who describes it as the essence of "integrative framework that includes a set of elements of polytechnic education, employment training, upbreeding, professional training and that also provides for the expansion of general cultural horizons of students and help them to master the technological culture ..." (Titov, 2005).

We join the number of those who consider the technological culture of a personality to be the result of technological education, i.e. its purpose.

\subsection{Structure of the personality's technological culture}

Having reviewed a number of studies on the structure of technological culture, we offer our interpretation of it. It is based on the position of P. R. Atutova about the nature of technological preparation (Atutov, 1997) and of the M. V. Petrova's description of the structure of technological culture (Petrova, 2000).

P. R. Atutov has formulated the essence of technological training as "the process of students' preparing for practical activity based on the formation process in their minds of the world's picture as an essential element of the development of attitudes and personality traits such as transformative thinking and creativity" (Atutov, 1997, p.127). This provision means that the technological world view, process thinking and creativity can be seen as components of the technological culture of the individual.

The technological world picture can be presented as a result of the interaction of the technosphere, sociosphere and biosphere (Petrova, 2000, p.54), which reflects the "totality of the means and methods of converting human activities in the concepts of scientific and technical knowledge" (Atutov, 1997, p.126). For example, in a secondary school scientific and technical knowledge forming the basis of the educational field "Technology" should be integrated with the scientific knowledge. In the structure of the overall picture of the world as described in the J. V. Shibanova's study, they presented as a picture of the world natural science, which is interpreted in different studies: 1) as a system of knowledge about nature, based on its laws (Shibanova, 1999, p.38); 2) as a result of the integration of separate world pictures: physical, chemical, biological and others (Starchanko, 2000, p.138). The technological world view, in its essence, is a system of accumulated public scientific and technical knowledge about the methods and means of reforming activities. It is not reflected in the minds of students unequivocally. In this regard, the result of the formation of the abovementioned competency in the student's mind may be referred to the technological outlook, that is an individual worldview understanding. Represented ratio of the concepts of "world view" and "outlook" was suggested in J. V. Shibanova's study (Shibanova, 1999, p.38). The usage of the term "world view" in our work is necessary for an adequate interpretation of the essence of the preparation process in terms of the individual's technological culture.

Technological thinking is defined by P. R. Atutov as "the thinking human ability to reform activities on creation of material and spiritual values" (Atutov, 1997, p.125). We have adopted this definition as a fundamental, since it belongs to the author's provisions of the essence of preparation process, which is under our consideration. Definition formulated in the given context is necessary to be used in order not to distort its understanding of the preparation process, which was studied by P. R. Atutov in his work, and thus be able to draw more valid conclusions about the goals of technological 
education. However, it should be noted that our definition of the process of thinking is not the only one. For example, in V. D. Symonenko's study the technological thinking is given as a "generalized and indirect individual's reflection of the scientific and technological sphere" (Simonenko, 1998, p.57).

Creative abilities of the individual learner, which are generated in the process of technological training, can be interpreted as the ability of people to work, which is characterized by using a set of "techniques, methods, analysis and synthesis of new products material and spiritual world" (Zaënchik et al., 2004, p.145] .

The work of M. V. Petrova presents another understanding. In her study, M. V. Petrova describes technological culture as a structure consisting mainly of technological outlook, technological excellence and technological behavior (Petrova, 2000, s.32-61). Let us draw the structural analysis of technological culture proposed by M. V. Petrova.

Technological outlook is "a stable position of the individual in relation to the person's transformative activity based on the integration of scientific, technical and human knowledge" (Petrova, 2000, p.55). It has its own structure, which includes a system of knowledge about the methods and means of reform activities, technological thinking and positions, defined as "the disciple's own opinion, his views, attitudes, assessment of transformative human activity level, which allows students to mobilize their natural ability to use their own experience for participation in technological activities" (Petrova, 2000, p.55).

Technological prowess - a skill, "based on the integration of methods and tools ... of converting activity ..." (Petrova, 2000, p.52). For a more complete identification of technological prowess we give a generalized definition of a mastery. Mastery reflects the "personality's traits acquired during his experience as a higher level of developed ... abilities in this area on the basis of flexible skills and creativity" (Platonov, 1984, p.64). In this context, we should take the author's position about the analyzed structure of the person's technological culture that the technological prowess requires from a student's consciousness a certain amount of knowledge and technological thinking (Atutov, 1997, s.52,56). According to these definitions of technological prowess to a large extent can be indicated by the manifestation of the student's creative abilities. It is worth to point out that technological prowess is inherent in every person, like creativity. In terms of goal setting, it's consistent to put the question not about the absence or presence of technological excellence but about the degree of its development.

Technological behavior is "a set of socio-economic, ethical, aesthetic norms and rules that ensure value grounds of transformative human activity" (Petrova, 2000, p.61). These regulations reflect mainly humanities from sociosphere constituting a technological worldview. Meaning of value bases is that they determine the direction of a schoolboy abilities' development to reform activities.

Technological behavior as a technological world has a structure consisting of an associative, regulatory and conversion level. Its main difference is the behavior in which, depending on the level of dominants presented association, rules and regulations, as well as creativity (Petrova, 2000, s.57-61).

\subsection{The reasons for the high efficiency of the process of education in the modern school}

School teachers find it difficult to explain the difference between the concepts of "labour" (the title of a subject until 1993). And "technology" (the title of the same academic subject since 1993). In practice, the education of children is carried out by the technique mastered by teachers during the Soviet period. In fact, "technology" is a more capacious concept, which includes labour as a component. The subject "Labour" involved the training of labor operations, methods and basic actions, whereas the "Technology" teaches children to work planning, namely: the selection of materials, the definition of the sequence of operations, the choice of tools, cost calculation and others.

Not all teachers organize technology in a secondary school pupils' project activities. The project simply does not fit the logic of labor (and not technology) training of children. In fact, the project was laid in the basis of the content of the educational field "Technology". Classes are expected to build in logic execution of a project. The project activity is directly related to the planning of work, and this is what distinguishes the subject of "Technology" on the subject of "Labour". It becomes obvious that organizing students' project activities, teachers priori implement technological (and not working) training children.

Technological education in professional school is characterized by considerable theorizing, heaviness to the demand in the labor market, by mismatch with the employers' requirements to the result of such education. Until now, we cannot say positively that Russia has a system of certification of qualifications of personnel and technical workers. While it could significantly adjust the work of schools in the common cause of formation and development of competencies among students and workers. It should be noted also there is a weak human capacity of pre-university professional education. This observation is true as to the regard to trainers and so to the managers of vocational training institutions. 


\section{Conclusion}

Technological culture of personality is the result of mastering of the individual's technological culture of a society. Technological culture of a society is the level of a society's development, due to the advances in science and technology. The level of a society's development determines the content of academic disciplines that make up the technological education. Changes in the technological culture of society entail changes in the individual technological culture. Accordingly, there is a causal link of technological education and technological culture of the individual.

In the context of the P. R. Atutova's provisions about the nature of technological preparation of personality's technological culture can be summarized as follows: technological education involves the transfer of knowledge to the students about the methods and means of reforming activities, the development of mental abilities that provide such activity, and creativity needed to create new material and spiritual values based on specified knowledge and thinking abilities to reform activities. The abovementioned relation of technological outlook values, technological thought and creativity allows us to represent them in the form of a tiered structure, where creativity is the highest level that develops the first two structures under the condition of permanent saturation.

These characteristics of the technological outlook, skills and behavior are generally similar to the following - they are inherent in technological outlook, technological thinking and creativity, which are largely determined by the development's level of the personal technological culture's structural components listed by M. V. Petrova.

So, the structure of the technological culture of personality is duplex. Horizontal substructure consists of the technological outlook, technological excellence and technological behavior. Vertical substructure includes technological outlook, technological thinking and creativity. Thus, the technological world view and process thinking and creativity determine the level of technological development outlook, technological excellence and technological behavior.

Insufficient development of quality assessment issues of technological education has led to the low efficiency of students' personal technological culture's formation.

Presented reasons causing the low efficiency of the educational process are massive, take much time to be resolved. Concerns about the situation is exacerbated by the transition of general education and vocational schools in the new federal state educational standards (FSES).

\section{Implications}

To summarize, we distinguish the main conclusions: Technological culture of a personality can be defined as the result of the assimilation of the individual technological culture of the society, the purpose of technological education.

Technological culture of personality can be represented as a two-tier structure: horizontal and vertical, where the horizontal is a substructure consisting of technological outlook, technological excellence and technological behavior and the vertical relationship reflects the technological outlook, technological thinking and creative abilities of students.

Among the reasons for the low efficiency of the process of education in a secondary school, we have identified: - a common misconception about the identity of the two concepts of "labour" and "technology"; - presentation of the teaching community of creative projects as a component of the educational content of the field "Technology", which can be neglected.

In the vocational school we have identified: - poor drafting communication theory and practice in the field; - inertia of technological education in relation to the demand in the labor market; - mismatch of technological education with the requirements of employers to the result of such education; - weak human capacity of a pre-university professional education.

Further research may be devoted to the study of problems of moderation of technological educational quality in the modern school.

\section{Acknowledgments}

The work is performed according to the Russian Government Program of Competitive Growth of Kazan Federal University.

\section{References}

Sedov, S. A., Valiev, I. N. Education, Science and Production Integration as a Condition of Dynamics of Social Interaction Stereotypes /I World Appl. Sci. J., 27 (Education, Law, Economics, Language and Communication): 325-328, 2013 
Grubb, W. N. 1995. Education through occupations. Educational leadership, 53, No. 3: 87-88.

Grubb, W. N. 1996. The new vocationalism. What it is, what it could be. Phi Delta Kappan, 77, No. 8: 535-546.

Dutton, M. 1996. Tech prep / school-to-work: career paths for all. The education digest, 61, \# 5: 56-59.

Wejk, S. L. 1996. Career and technology studies crossing the curriculum. Educational leadership, 53, No. 8: 50-53.

Titov, A. V. Building a system of concepts of technological education as a condition for improving the quality of students' knowledge: Dis. ... PhD. ped. Sciences / A. V. Titov. - Izhevsk, 2005. - 220 p.

Atutov, P. R. On the technological thinking / P. R. Atutov // Russian secondary school: Problems and Prospects: Sat. Articles / The IEC RAO. - M., 1997. - S. 125 - 128.

Petrova, M. V. Integration processes in shaping of the students's technological culture : Thesis. ... PhD. ped. Sciences / M. V. Petrova. Makhachkala, 2000. - 222 p.

Shibanova, J. V. Didactic principles of integration of Science subjects in a secondary school: Dis. ... PhD. ped. Sciences / J. V. Shibanov. - Ulan-Ude, 1999. - 165 p.

Starchanko, S. A. Theoretical basis of the integrative content of science education at the Lyceum: Dis. ... Dr. ped. Sciences / S. A. Starchanko. - Ufa, 2000. - 421 p.

Simonenko, V. D. Fundamentals of technological culture. Teacher's Book / V. D. Symonenko. - Bryansk: BPTU, 1998. - 268 p.

Zaënchik, V. M. Basis of creative design activity: Methods and Organization: A Textbook for the studio. Higher. Proc. institutions / V. M. Zaënchik, A. A. Karachëv, V. E. Shmelyoff. - M .: Publishing Center "Academy", 2004. - 256 p.

Platonov, K. K. Concise Dictionary of psychological concepts: Textbook for schools vocational training / K. K. Platonov. - 2nd ed., Revised. and ext. - M .: Higher School, 1984. - 174 p. 